\title{
Natural history, biogeography, and endangerment of Hawaiian dry forest trees
}

\author{
Stephanie Pau $\cdot$ Thomas W. Gillespie $\cdot$ Jonathan P. Price
}

Published online: 2 August 2009

(C) Springer Science+Business Media B.V. 2009

\section{Erratum to: Biodivers Conserv DOI 10.1007/s10531-009-9635-1}

In the original version of this article under the "Discussion" section, the third paragraph currently reads:

"Seven dry forest taxa with hermaphroditic breeding systems, autochorous dispersal, conspicuous flowers, and dry fruit have range sizes of five islands or larger are federally at risk of endangerment: Caesalpinia kavaiensis, Erythrina sandwicensis, Hibiscus brackenridgei, Hibiscus kokio, Sesbania tomentosa, Sida fallax, and Sophora chrysopylla."

Should read:

"Even relatively common species, Erythrina sandwicensis, Sida fallax, and Sophora chrysophylla, have traits consistent with endangerment (hermaphroditic breeding systems, autochorous dispersal, conspicuous flowers, dry fruit, and range sizes of five islands or larger)."

In the "Results" section under the fourth paragraph, the sixth sentence currently reads:

"Hermaphrodism, autochory, conspicuous flowers, and fleshy fruit had higher percentages of taxa at risk compared to other categories in their group."

Should read:

"Hermaphrodism, autochory, conspicuous flowers, and dry fruit had higher percentages of taxa at risk compared to other categories in their group."

The online version of the original article can be found under doi:10.1007/s10531-009-9635-1.

S. Pau $(\bowtie) \cdot$ T. W. Gillespie

Department of Geography, University of California Los Angeles, Los Angeles, CA 90095-1524, USA e-mail: paus@ucla.edu

T. W. Gillespie

e-mail: tg@geog.ucla.edu

J. P. Price

Department of Geography and Environmental Studies, University of Hawaii-Hilo, Hilo,

HI 96720, USA

e-mail: jpprice@hawaii.edu 